\title{
LOS SOFISTAS: LA FILOSOFÍA COMO TERAPIA
}

\author{
THE SOPHISTS: THE PHILOSOPHY AS THERAP
}

Hector Ponce Bodino*

\begin{abstract}
RESUMEN
El artículo recorre los pasos de Grecia clásica por la mitología, los presocráticos, la tragedia y los sofistas hacia la distinción de leyes naturales y leyes sociales; distinción que permitió criticar al statu quo justificado en un orden natural.
\end{abstract}

\section{PALABRAS CLAVES}

Presocráticos, trágicos, sofistas, ley convencional.

\begin{abstract}
The article covers the steps of classical Greece through the mythology, the pre-Socratic, tragedy and the Sophists to the distinction of natural laws and social laws; distinction that allowed criticize the status quo justified in a natural order.
\end{abstract}

\section{KEYWORDS}

Pre-Socratic, tragic, sophists, conventional law.

* Universidad Peruana de Ciencias Aplicadas: heaponce@yahoo.es 
Numerosas discusiones intelectuales avanzan si los conceptos utilizados promueven algunas veces distinciones conceptuales y diferencias flexibles y graduales, no maniqueas; y otras veces las controversias de conceptos dicotómicos, binarios, entorpecen y paralizan la investigación o la conversación. En este artículo se analizará el inicio de la distinción entre leyes naturales y leyes convencionales aportada por los sofistas que permitieron criticar a las instituciones tradicionales. Aún hoy se censuran o avalan prácticas sociales por no imitar el orden natural, como por ejemplo la práctica de la mutilación genital femenina o la creencia de que finalmente el modelo económico sigue la natural senda darwiniana en su sentido más agresivo. Pero cuando los comportamientos sociales dejan de ser presentados como naturales, en el sentido de inevitables, y son considerados convencionales, los individuos que conforman las sociedades, pueden responsabilizarse por el curso que deciden darle a sus vidas. Esta es una manera de realizar cambios sociales legados por el ingenio de los sofistas.

En su versión crítica, la filosofía tiene el propósito de advertir los problemas que subyacen en el uso incauto o malintencionado de algunos conceptos y en su versión terapéutica - explicitada por Wittgenstein a partir de las Investigaciones filosóficas - el quehacer filosófico tiene la finalidad de desenredar los malentendidos conceptuales. Hacer filosofía sería la disposición y el ejercicio constante, un entrenamiento lógico, que consiste en analizar argumentos y disolver enredos mentales.

Así sucedió cuando los sofistas en el siglo V a.C. se ocuparon de sopesar, a través de argumentos, el cúmulo de sentimientos en tensión y convulsos heredados de las descripciones geniales de los poemas de Homero y de la tensión psicológica de las hermosas tragedias de Esquilo, Sófocles y Eurípides. La tarea no debió de ser nada fácil para los sofistas, pues se trataba nada menos que de aclarar -si eso es posible- la complejidad de las emociones que se encuentran anudadas, por ejemplo, en quien no halla consuelo por la pérdida de un ser querido, en quien se siente resignado ante el destino e incluso en quien mantiene y alimenta con tesón un fogoso rencor. A continuación, se recordará, en líneas generales, algunas creencias de los mitos griegos y que los presocráticos reformularon, y cuáles fueron las nuevas aristas que encaró la tragedia griega y la propuesta de los sofistas.

\section{Los dioses de Homero}

En el siglo IX a. C. los griegos creían que los terremotos y los eclipses, las lluvias y los maretazos eran causado por los dioses; pero no sólo los sucesos del mundo, sino también las motivaciones y estados mentales de las personas eran efectos del influjo de Zeus, Afrodita o Dionisio. Las personas eran, en el mejor de los casos, coautoras inconscientes de lo que padecían y, en el peor de los casos, eran simplemente incapaces de elegir sus vidas. No decían oraciones como "yo deseo llegar a determinado lugar", sino más bien "mis pies me llevaron a tal lugar" (Snell, 1965, p. 26) ${ }^{1}$. Esto sucedió porque aún no se distinguía entre la actividad corporal y la mental, y menos aún, entre el orden de la naturaleza y el orden de la convención. Los acontecimientos se interpretaban como predestinados, y así se muestran en la obra de Homero. En aquella época,

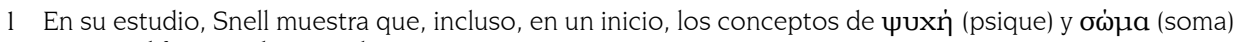
no eran diferenciados para los griegos. 
los griegos no se consideraban del todo como organizadores de sus vidas, pues los dioses intervenían cotidianamente en sus deseos. Se podría contra-argumentar que sí existía la idea de elección, sólo que atribuida a los dioses; pero es llamativo que los mismos dioses no gobernaran del todo sus propias vidas, pues estaban limitados por el destino ${ }^{2}$. El caso es que las acciones humanas aún eran explicadas de la misma forma que las acciones de los cuerpos celestes: ambas seguían un orden divino e inmutable.

\section{La naturaleza es racional}

La explicación mitológica, de algún modo recopilada por Homero, descansaba en la autoridad privilegiada de los poetas iluminados cuyos poderes les permitían acceder a leyes que, para el resto de los mortales, eran incognoscibles. Los primeros filósofos, en cambio, apostaron por el razonamiento del ser humano y en la posibilidad de explicar la realidad. Dicho sea brevemente, la transición de la mentalidad mítico-religiosa a la filosófica, en Grecia, no significó un hecho traumático, pues, como sostuvo Octavio Paz, "la originalidad de la religión griega reside en ser libre creación de poetas y no especulación de una clerecía. Y el ser creación poética libre, y no dogma de una Iglesia, permitió después la crítica y favoreció el nacimiento del pensamiento filosófico" (Paz, 1972, p. 198).

El nacimiento de esta nueva actitud fue favorecida, entre otros eventos, por las reformas de Solón que distribuyeron a la población por sus bienes y ya no por su linaje. Comenzó a ser indiferente si el autor de una explicación provenía de una casta privilegiada, una familia de nobles con atributos mágicos, y más bien se buscaban explicaciones lógicas comprensibles a todos los ciudadanos dispuestos a esforzarse intelectualmente. Se eliminaba así la arbitrariedad de los aristócratas y de los estamentos sociales y, análogamente al ideal democrático, la filosofía explicaba al Universo como gobernado por leyes válidas en todos los lugares, tal como explica Vernant (1965, pp. 82-107).

De este modo, los primeros filósofos, llamados presocráticos, explicaban que el Universo, a pesar de su aparente diversidad, poseía un orden natural accesible, en principio, a la razón humana. La revolución intelectual que significó la filosofía en relación con el mito, consistió en ofrecer explicaciones que lograsen hacer familiar los eventos nuevos. Para ello se necesitaba encontrar lo permanente en el Universo a pesar de los cambios que presenciaban los sentidos, señala Guthrie (1980, p. 30), y a la caza de ese orden inalterable se dedicaron los filósofos presocráticos.

Sin embargo, los resultados de las indagaciones especulativas que realizaron los presocráticos, siempre enalteciendo a la razón y desvalorizando la información registrada por los sentidos, debieron de ser contra-intuitivas y, peor aún, muy ajenas a la vida práctica de los griegos. Los presocráticos daban prioridad a la razón y despreciaban a los sentidos como instrumentos de conocimiento, y, así, el ciudadano, ante el dilema de creer con Heráclito en que existía una

2 Snell también observa que no sólo a los dioses se les proyectó cualidades humanas, sino también a la naturaleza, como se aprecia en metáforas tales como "el tiempo vuela", "el agua corre", "el viento sopla". Pero así como las cosas se humanizan, también los hombres se cosifican, como cuando se dice "la piedra resiste". Una de las ideas del autor es que de la misma manera en que las piedras pueden antropomorfizarse, así también los hombres pueden petromorfizarse (Snell, 1965, p. 284). 
armonía oculta a los sentidos o de creer con Parménides en que el Universo no cambiaba o de creer con Demócrito en que el Universo estaba formado por átomos imperceptibles, perdió interés en esas discusiones abstractas y de repercusiones alejadas del ámbito ético y político. Heráclito ironizaba sobre el conocimiento distorsionado de la gente y contaba la burla que recibió el sabio Homero por unos niños que mataban piojos. Homero les preguntó qué habían traído del viaje y ellos, crujiendo los piojos, respondieron: "Las cosas ocultas que no hemos visto ni cogido, las traemos" (Colli, 2000. p. 71$){ }^{3}$

Pero al ciudadano dejaba de interesarle los asuntos del cosmos y le atraían los temas jurídicos y morales, pues, a causa de una mayor estabilidad en el régimen democrático, la mayoría tuvo la oportunidad de participar en las discusiones políticas. Así, en la historia de la filosofía, este tránsito se conoce el movimiento que se da desde el interés exclusivo por reflexiones sobre la naturaleza hacia el interés por los asuntos humanos.

\section{Del naturalismo al humanismo: la tragedia}

Para la sensibilidad de los trágicos, ni la explicación del mito ni la de los presocráticos se ocupaban adecuadamente del sufrimiento y, menos aún, mostraban los matices y las contradicciones del ser humano. Mientras Homero describía sin indignación las intervenciones de los dioses sobre la humanidad, los presocráticos no analizaron las circunstancias existenciales de las personas. La tragedia sí volcó su atención a los temas éticos y existenciales que fueron obviados por sus antecesores, aunque las fuerzas de la naturaleza y las fuerzas de las convenciones sociales aparecieron bajo una forma entremezclada y ambigua, sin distinciones. Se presentaron los dilemas humanos como una tensión entre caminos contradictorios, sin necesidad de mostrar la validez absoluta de una tesis, sino con la finalidad de mostrar varios discursos opuestos y en combate.

Para Esquilo, por ejemplo, el dolor humano se producía cuando se negaba el orden del destino y la expiación se lograba al comprender el orden inexorable; y para Sófocles el ser humano está encarcelado en el sufrimiento: ya sea que cumpla el orden del destino o no, igual sufrirá. Por eso la tragedia permitió encarar el desgarramiento - no advertido ni por el mito ni por los presocrático - entre el destino y la voluntad humana, y de ahí que en Antígona se pueda leer una frase de gran poder: "Endereza tu destino" (Sófocles, 2001, p. 175). Para Eurípides, el último trágico, vivir es sufrir, y los dioses ni el destino se lo proponen, todo es sinsentido, todo es absurdo.

El héroe trágico empezaba a preguntar acerca de la responsabilidad de sus acciones en dos direcciones: ¿debemos seguir las leyes ciegas del destino o es posible modificarlas? Si el individuo podía elegir su forma de vida, entonces era responsable; pero si no podía elegir sus

3 Fragmento B 56: "Se equivocan los hombres respecto del conocimiento de las cosas manifiestas, como Homero, quien pasó por ser el más sabio de todos los griegos. A este, en efecto, lo engañaron unos niños que mataban piojos y le decían: cuantos vimos y cogimos, a esos los dejamos; cuantos ni vimos ni cogimos, a esos los llevamos". Según Karl Popper, Heráclito fue tribal al no diferencias entre leyes de la naturales y leyes sociales, y defendió la causa aristocrática: "Los ciudadanos adultos de Éfeso tendrían que ahorcarse todos, uno por uno, y dejar el gobierno de la ciudad en manos de los niños". (Cfr. Popper, 1945, p. 28). 
acciones por causa del destino, entonces era víctima.

La conciencia trágica planteaba, además, el escenario de tal manera que sólo permitía la contradicción entre la existencia de leyes inexorables del destino y la existencia de la libertad del individuo. Para los trágicos aún resultaba incomprensible que el ser humano tuviese libertad en un universo de leyes naturales cuyos fines estaban predestinados, pero - y no tenían por qué pretenderlo - en lugar de desenredar el problema, al igual que Heráclito, sugirieron que la existencia estaba signada por fuerzas contradictorias que formaban una armonía de opuestos: "el universo está en armonía y tensión como lo está la cuerda del arco o de la lira". (fragmento 51).

De esta manera, la tragedia no se proponía marcar un trazo nítido y definitivo entre el destino y la libertad, entre un orden inmodificable y la capacidad de modificar voluntariamente la vida, sino más bien subrayaba las contradicciones y no deseaba imponer ninguna solución. De allí que el espectador de Antígona asistía al conflicto de los personajes, a sus enredos y a sus desgarros, causados, en parte, pues aún era confuso el sentido que adquiría la palabra justicia en boca de Antígona y el sentido de la misma palabra en las manos de Creonte (Vernant, 2002). A veces el espectador comprendía la palabra justicia como el orden impuesto por las divinidades, y otras veces la entendía como el orden creado por las instituciones de los hombres, y esta oscilación del significado de la justicia se debía, en buena cuenta, a que los griegos transitaban de una situación sosegada a una nueva época convulsa por las guerras con los persas y por las discusiones jurídicas y morales al interior de su propia vida política, razón por la que el interés en asuntos prácticos se intensificó, y los jóvenes, que vieron ahí la oportunidad de ser parte de la política y de ser los agentes de sus vidas, buscaron a los sofistas para que sean sus maestros y los adiestraran en las polémicas éticas y políticas.

\section{Sofistas: la filosofía como terapia}

¿Qué enseñaban los sofistas a esos jóvenes que los buscaban para que los entrenasen en las discusiones? A desenvolverse y argumentar sobre temas políticos y jurídicos, y si bien hubo sofistas que impartieron esas clases de oratoria con virtud, hubo otros que hicieron todo lo posible para ganarse la mala fama de negociantes, pues se jactaban de tener el poder de enseñar el arte de la retórica y de la elocuencia en el sentido demagógico del término y además, al negar que exista un mínimo de objetividad en las pautas morales, algunos sofistas hicieron de los litigios jurídicos un simple ejercicio retórico y hechizante, jugando a transformar el argumento más débil en el más fuerte. Ese juego retórico se ve en una discusión banal entre un profesor sofista y su alumno:

Una vez concluida las enseñanzas retóricas, el maestro Tisias pidió a su discípulo Corax que le pagara. El discípulo respondió que no pagaría en ningún caso. Si había aprendido, entonces podría convencer al maestro de no pagarle. Si no convencía al maestro, entonces no tenía que pagar por una mala enseñanza.

El maestro Tisias retrocedió, alarmado ante su discípulo Corax, y luego se dispuso a contra-atacar. El discípulo debía pagar en cualquier caso. Si el discípulo lograba convencer al maestro de no pagar, entonces esto demostraba que había aprendido. Si el discípulo no lograba convencer al maestro, entonces 
tendría que pagar por el simple hecho de no haber convencido. (Xirau, 1964, pp. 40-41) ${ }^{4}$.

Pero, como se ha indicado líneas arriba, en el interés por demarcar el ámbito cultural del ámbito natural, no todos los sofistas tenían esa disposición a la demagogia. Protágoras es un buen representante de alguien que, en el plano pedagógico, de verdad deseaba que quienes ingresaran a la política fuesen elocuentes, en el sentido de buenos argumentadores, y, en la dimensión filosófica, también personificó a quien de verdad creyó que era imposible conocer cómo son las cosas en sí mismas al margen de la experiencia de cada individuo, y se le recuerda por la frase "El hombre es la medida de todas las cosas". Él negaba que se pudiera conocer el orden natural del mundo al margen de la percepción de cada sujeto, porque cada individuo tenía la autoridad para afirmar si determinado objeto se le presentaba bajo diferentes cualidades perceptivas, como frío, chirriante, lejano, salado o inodoro. Según Protágoras, si una persona percibe el sabor de un pan como desagradable y otra como de buen sabor, no hay manera de conocer el sabor del pan al margen de cada individuo. Ninguna opinión es más verdadera que la otra, dirá Protágoras, no obstante, y es una importante aclaración, sí habrá opiniones más útiles que otras. Esta última idea, proto-pragmatista, señalaba que, por ejemplo, muchas veces para un enfermo el remedio es repugnante y, en cambio, para un médico es necesario; preguntarse por cuál es la opinión verdadera de entre los dos sería inútil, pero lo que sí se puede hacer es buscar cuál es la opción práctica, y aquí radica la analogía entre la filosofía y el fármaco: "con la educación ha de procurarse el cambio del estado peor al mejor. [Y] mientras el médico produce el cambio mediante fármacos, el sofista lo produce mediante discursos" (Platón. Teeteto, 157A).

Durante sus viajes los sofistas veían asombrados que aquello que constituía un hecho objetivo e indubitable en una cultura no lo era en otras culturas (Cópleston, 2001, p. 96) y la filosofía comenzó a dar un giro antropológico. De modo que, si los presocráticos se ocuparon de explicar a la naturaleza por medio de leyes válidas en todas las culturas, los sofistas buscaron subrayar las diferencias que existían entre las convenciones sociales de diferentes pueblos. Así lo hizo Heródoto quien, sin ser sofista sino historiador del siglo V, escribió sobre el arraigo que genera en cada pueblo las propias costumbres y tradiciones, y situó una anécdota entre el rey persa Darío I y los griegos.

En cierta ocasión hizo llamar Darío a unos griegos, que eran sus vasallos, y les preguntó por cuándo dinero se comerían a sus padres una vez muertos. Ni por todo el oro del mundo, respondieron. Darío hizo llamar a unos indios titulados calatias, entre quienes es ceremonial comer el cadáver de sus propios padres, y les preguntó si quemarían los cadáveres de sus padres, y los calatias suplicaron a gritos que no dijera por los dioses tal blasfemia. (Heródoto, 1971, pp. 128-129)55.

De encuentros frecuentes con otros pueblos, como el narrado por Heródoto, los griegos aprenderían a ser tolerantes

4 He modificado el estilo del texto original del mexicano Xirau.

5 He modificado el estilo del traductor. El texto continúa así: "iTanta es la prevención a favor del uso y de la costumbre! De suerte que, cuando Píndaro hizo a la costumbre árbitra y déspota de la vida, habló a mi juicio como filósofo más que como poeta". 
frente a las diversas tradiciones, y esto, según lo suscribe Karl Popper (2005), en gran parte, pudo motivar el brote del arte, la filosofía, la ciencia y de la civilización griega. Los sofistas, al ser maestros viandantes, habían conocido diversas civilizaciones y, por ello, cuestionaron el hecho de que la cultura griega - sus creencias, sus valores y sus costumbres hubiese sido, ella sí, creada a partir de un modelo natural. Las leyes que regulaban los comportamientos sociales no eran iguales a las leyes que regulaban los movimientos de los planetas; y las leyes de los asuntos humanos eran convencionales en tanto que eran frutos de las costumbres colectivas de las diversas civilizaciones y épocas, de manera que no podía alegarse ya un único orden correcto.

\section{Naturaleza y convención}

Recapitulando los tres momentos antes mencionados, a la pregunta acerca de cómo está constituido el cosmos, se ha visto que el mito creyó que por leyes caprichosas de los dioses que a veces éstos modificaban; los presocráticos, por leyes inmanentes; y la tragedia, sin verse motivada a diferenciarlas, presentó que en el cosmos había dos tipos de leyes, pero amalgamadas: las que los dioses imponían a los hombres y las que eran forjadas por los seres humanos. Mientras Sófocles, en sus tragedias, preguntaba si existían leyes superiores a los caprichos de los dioses (Paz, 1972). Eurípides, también con obras teatrales, abandonaba el presupuesto del destino y ello implicaba, para él, asumir que la vida era absurda. Los sofistas, por su lado, tenían que responder en qué sentido podían existir leyes no divinas, y si al negarlas era inexorable que la vida fuese irracional. Prefirieron reinterpretar la pregunta de Sófocles de esta manera: ¿los dioses existen o dependen de las creencias culturales? El presocrático Jenófanes había escrito un texto que, si bien apuntaba a una reflexión monoteísta, debió de ser un punto de referencia para los sofistas cuando éstos se ocupaban sobre la diversidad de creencias y cosmovisiones entre los pueblos.

Los etíopes dicen que sus dioses son bajos y negros, mientras para los tracios sus dioses tienen los ojos azules y el pelo rubio. Si los bueyes, los caballos o los leones tuvieran manos y fueran capaces de pintar con ellas y de hacer figuras como los hombres, los caballos dibujarían las imágenes de los dioses semejantes a las de los caballos y los bueyes semejantes a las de los bueyes (1994, pp. 247-248).

Acerca de la encrucijada que plasmaban las obras de Eurípides, dilema que planteaba una de dos, o creer en la existencia tiene un plan predefinido por los dioses o creer que la existencia es absurda, los sofistas sostuvieron que el opuesto del destino no era necesariamente el absurdo, sino lo convencional. Si bien es cierto que, en el terreno teórico, los sofistas desembocaron en el escepticismo acerca de si se podía conocer objetivamente al mundo, también es cierto que propusieron distinguir el orden natural del cultural. Las leyes de las culturas, lejos de ser obra de dioses, de la naturaleza o del destino, fueron comprendidas como creadas por el resultado de consenso y disensos entre las personas. De esta manera se comprendió que, si las leyes de la naturaleza eran inmutables, no sucedía lo mismo con las leyes de la cultura, pues, al ser éstas el resultado de convenciones, de pautas pactadas por todos los ciudadanos, no era necesario entonces padecerlas pasivamente, sino más bien debían transformarse para el bienestar de la comunidad. Los sofistas facilitaron, así, el camino para criticar el statu quo que, hasta hoy en día, tiende a justificarse en 
que supuestamente sigue el orden natural que debe seguir la vida social.

No constituyeron una escuela dogmática, pero todos sostuvieron la noción de ver a los argumentos como fármacos. En esa diversidad de ideas y argumentos, algunos sofistas pensaron que las convenciones sociales restringían negativamente la naturaleza del ser humano (para Glaucón la civilización reprime los instintos, y si pudiéramos actuar impune e invisiblemente, todos robaríamos), y otros, por el contrario, sostuvieron que esas convenciones significaban un progreso de la civilización (Protágoras), aunque otros advirtieron que la cultura beneficia al más fuerte y no debía ser así (Trasímaco).

También el grado de escepticismo entre ellos fue distinto; hubo sofistas para quienes las convenciones eran dañinas en el desarrollo de las diferentes potencialidades de los individuos (para Gorgias la civilización pone de cabeza lo natural, y lo natural es que el más fuerte domine a los débiles); y hubo sofistas para quienes las convenciones eran beneficiosas por lograr acuerdos básicos entre ciudadanos (Protágoras). En su diversidad, los sofistas afilaron el aspecto práctico de la filosofía y, en su mejor versión, fue el ejercicio intelectual de escuchar y ofrecer razones; la mayoría de los sofistas, además, comparó su trabajo con el de los médicos que dan fármacos, pero para remediar los males que producen en las mentes la confusión de ideas.

\section{REFERENCIAS}

Colli, G. (2000) El nacimiento de la filosofía. Barcelona: Tusquets editores.
Copleston, F. (2001) Historia de la Filosofía. Grecia y Roma. Barcelona: Ariel.

Eggers, C. y V. J. (Comp.) (1978) Los filósofos presocráticos. Madrid: Gredos.

Guthrie, W. (1980) Los filósofos griegos. México: FCE.

Heródoto (1971) Los nueve libros de la historia. México: Porrúa.

Kirk, C.; Raven, J. y Schofield, M. (1994) Los filósofos presocráticos. Historia crítica con selección de textos. Madrid: Gredos.

Paz, O. (1972) El arco y la lira. México: FCE.

Platón (1992) Diálogos. Parménides, Teeteto, Sofista, Político. Madrid: Gredos.

Popper, K. (2005) El mito del marco común: en defensa de la ciencia y la racionalidad. [1994] Barcelona: Paidós.

Popper, K. (2006) La sociedad abierta y sus enemigos [1945] Barcelona: Paidós.

Snell, B. (1965) Las fuentes del pensamiento europeo: estudio sobre el descubrimiento de los valores espirituales de Occidente en la antigua Grecia. Madrid: Razón y fe.

Sófocles (2001) Áyax, Las traquinias, Antígona, Edipo rey. Madrid: Alianza Editorial.

Vernant, J. (1965) Los orígenes del pensamiento griego. Buenos Aires: Eudeba.

Vernant, J. (2002) Mito y tragedia en la Grecia antigua. Barcelona: Paidós.

Xirau, R. (1964) Introducción a la historia de la filosofía. México: UNAM. 